\title{
Haematuria in patients with bleeding disorders
}

\author{
G.R. Ramayya, D. Hemingway and A.D. Desmond \\ Department of Urology, Broadgreen Hospital, Thomas Drive, Liverpool L14 3LB UK
}

\begin{abstract}
Summary: Patients with bleeding disorders or who are anticoagulated may present with haematuria. Failure to investigate such patients when they first present may delay the diagnosis and treatment of a serious genito-urinary pathology.
\end{abstract}

\section{Introduction}

Haematuria is not an uncommon occurrence in patients who suffer with bleeding disorders or who are anticoagulated. This is often regarded by the unwary clinician as having no sinister significance and can be easily ignored. It cannot be overstated that this important symptom should not be overlooked in such patients and should be fully investigated.

We would like to present four cases each suffering with a different type of bleeding ailment who presented to the Urology Department at Broadgreen Hospital with frank haematuria. When investigated, all these patients were found to have a serious underlying pathology which was unrelated to their haematological disorder.

\section{Case reports}

\section{Case 1}

A 70 year old man suffering with hereditary haemorrhagic telangiectasia presented with a 4 day history of frank haematuria. He had been admitted into hospital on several occasions in the past with episodes of severe epistaxis.

On examination he looked pale. There were several areas of telangiectasia on his face, nose and on his lips. His haemoglobin concentration was $9.1 \mathrm{~g} / \mathrm{dl}$ and his blood urea and electrolytes were within normal limits.

An intravenous urogram revealed the presence of a filling defect in the bladder which was obstructing his right ureter. Cystourethroscopy confirmed the presence of a papillary tumour involving the right side of the bladder. This was resected endoscopically. The histological features of the specimen were those of a non-invasive moderately differentiated transitional cell carcinoma. Since then he has undergone regular

Correspondence: G.R. Ramayya, F.R.C.S., F.R.C.S.(Ed.) Accepted: 25 June 1985 cystoscopy and there has been no evidence of any recurrence.

\section{Case 2}

A 50 year old severe haemophiliac (Factor VIII less than $2 \%$ ) presented with a 5 day history of frank haematuria associated with colicky pain in his left loin. In the past he had been admitted to hospital many times with haemarthrosis involving various joints. In addition he had suffered with two previous episodes of haematuria and was investigated and treated medically for a duodenal ulcer. No abnormality was detected on clinical examination, apart from fullness in the left loin.

An intravenous urogram revealed the presence of a massive left hydronephrosis due to pelvi-ureteric junction obstruction. A DMSA scan showed a scarred left kidney and the differential function was $25 \%$ compared to $75 \%$ on the right side. It was therefore thought that the pelvi-ureteric junction should be refashioned and this was performed under the cover of Factor VIII with the appropriate haematological backup. Although the haematuria persisted in the post-operative period, it subsequently cleared and the patient made an uneventful recovery.

\section{Case 3}

A 70 year old man was admitted with clot retention following 4 days of frank painless haematuria. The patient was taking digoxin and phenindione for mitral valve disease. Clinical examination was unremarkable apart from an enlarged and tender urinary bladder. The patient was catheterized to relieve his clot retention and the haematuria was controlled using continuous irrigation with normal saline. Investigations revealed a prothrombin index of 3.4 (therapeutic range 2.5-3.5), and his kaolin cephalin coagulation time was $46 \mathrm{~s}$ (therapeutic range $40-60 \mathrm{~s}$ ). 
An intravenous urogram showed a filling defect involving the right side of the bladder. Cystourethroscopy revealed the presence of a papillary tumour around the right ureteric orifice and extending laterally to involve the right side of the bladder. This was resected endoscopically and histology confirmed a moderately differentiated non-invasive transitional cell carcinoma of the bladder. Since then he has had regular check cystoscopies.

\section{Case 4}

A 74 year old man known to suffer with chronic lymphatic leukaemia which was complicated with thrombocytopenia, was referred to the Urology Department for investigation and treatment of recurrent episodes of frank haematuria. On examination he looked ill. There were multiple bruises and purpuric spots on his upper and lower limbs. Examination of the abdomen revealed an enlarged liver and spleen. The patient's haemoglobin was $10.4 \mathrm{~g} / \mathrm{dl}$, his white cell count was $28.3 \times 10^{9} / 1$ and the platelet count was $43,000 / 1$. An intravenous urogram did not show any abnormality. The patient underwent cystourethroscopy which revealed three papillary lesions in the bladder. These were resected endoscopically and the

\section{References}

ANTOLAK, S.J. \& MELLINGER, G.T. (1969). Urologic evaluation of haematuria occuring during anticoagulant therapy. Journal of Urology, 101, 111.

BECK, P. \& EVANS, K.T. (1972). Renal abnormalities in patients with haemophilia and Christmas disease. Clinical Radiology, 23, 349.

INGRAM, G.I.C., BROZOVIC, M. \& SLATER, N.G.P. (1982). In Bleeding Disorders, 2nd Edition. p. 40. Blackwell Scientific Publications: Oxford.

PRENTICE, C.R.M., LINDSAY, R.M., BARR, R.D., FORBES, histology confirmed the presence of a transitional cell carcinoma.

\section{Discussion}

Patients with bleeding disorders bleed into the urinary tract, and this complication is often accepted as an innocuous manifestation of their bleeding disorder (Beck \& Evans, 1972; Wright et al., 1971). It often occurs as a spontaneous phenomenon and is transient (Prentice et al., 1971). This is the reason why investigation is recommended only if haematuria is recurrent or unusually prolonged (Thompson, 1977; Ingram et al., 1982).

In one series (Antolak \& Mellinger, 1969), 13 out of 16 patients on anticoagulants who had presented with haematuria were found to have urological disease, 9 of whom had only microscopic haematuria.

The above cases, therefore, illustrate the need for complete investigation of patients suffering with bleeding disorders, or who are anticoagulated when they first present with haematuria. Failure to do this can delay the diagnosis and treatment of a serious genito-urinary pathology.

C.D., KENNEDY, A.C., McNICOL, G.P. \& DOUGLAS, A.S. (1971). Renal complications in haemophilia and Christmas disease. Quarterly Journal of Medicine, New Series, $X L$, $157,47$.

THOMPSON, R.B. (1977). In Diseases of the Blood. p. 741. Churchill Livingstone: Edinburgh.

WRIGHT, F.W., MATTHEWS, J.M. \& BROCK, L.G. (1971). Complications of haemophiliac disorders affecting the renal tract. Radiology, 98, 571. 